\title{
Desenvolvimento sustentável do Marajó, Pará: uma visão a partir do Barômetro da Sustentabilidade
}

\section{Sustainable development of Marajó, Pará: an overview based on the Barometer of Sustainability}

Patrick Diniz Alves Quintela - Mestrando em Ciências Ambientais pela Universidade Federal do Pará. Bacharel em Agronomia pela Universidade Federal Rural da Amazônia. E-mail: patrick.agronomia@gmail.com

Peter Mann de Toledo - PhD in Geology - University of Colorado. Mestrado em Geociências pela Universidade Federal do Rio Grande do Sul e pesquisador do INPE lotado na Coordenação de Ciência do Sistema Terrestre.E-mail: peter.toledo@hotmail.com

Ima Célia Guimarães Vieira - Doutora em Ecologia - University of Stirling. Mestrado em Genética e Melhoramento de Plantas pela Universidade de São Paulo e Pesquisadora do Museu Paraense Emílio Goeldi. E-mail: ima@museu-goeldi.br

\section{Resumo}

Este trabalho apresenta uma análise da sustentabilidade de 16 municípios que compõem a mesorregião do Marajó, Pará. A pesquisa utilizou o Barômetro da Sustentabilidade (BS) como ferramenta de análise e empregou 20 indicadores para o bem-estar humano (dimensão socioeconômica) e 06 para o bemestar ecológico (dimensão ambiental). A abordagem do Barômetro da Sustentabilidade indicou que os municípios do Marajó variam de "potencialmente insustentável” a “intermediário". O Marajó mostrou um quadro de desequilíbrio em relação ao nível de sustentabilidade dos municípios, e a isso associamos a ineficácia dos resultados de políticas públicas integradas aliada à discrepância dos diferentes modelos de gestão municipal.

\section{Palavras-chave}

Sustentabilidade. Marajó. Indicadores. Desenvolvimento Sustentável.

\begin{abstract}
This paper presents an analysis of the sustainability of 16 cities from the Marajó region, State of Pará. We used the Barometer of Sustainability as an analytical tool and applied 20 indicators for human well-being (human dimension) and 06 for ecological health (environmental dimension). The Barometer approach shows a range of sustainability of Marajó municipalities between "potentially unsustainable" and "intermediate". The Marajó displays a disequilibrium in relation to the level of sustainability of the municipalities, and to this we associate the inefficiency of the results of integrated public policies combined with the discrepancy of the different municipal management models.
\end{abstract}

\section{Keywords}

Sustainability. Marajó. Indicators. Sustainable Development 


\section{INTRODUÇÃO}

A mesorregião do Marajó, no estado do Pará, apresenta-se como um território com atributos que o singularizam no cenário nacional. É constituído por um mosaico de ecossistemas dinâmicos, com uma rica biodiversidade. A tradição e a modernidade coexistem espacialmente entre interesses diversos e conflitantes - a maior parte dele é Área de Preservação Ambiental, possui grandes áreas de produção pecuária e elevada população de comunidades tradicionais que vivem do extrativismo vegetal, pesca e agricultura - e, desde 2006, tem havido tentativas de implementação de novos modelos de gestão e ordenamento territorial (BRASIL, 2007; 2012), visando o planejamento e a gestão social de políticas públicas para o desenvolvimento sustentável.

É fato que o desenvolvimento sustentável está presente como questão fundamental nas políticas públicas e considerando-se a sustentabilidade como um conceito dinâmico que engloba diferentes dimensões (VAN BELLEN, 2004), espera-se que não exista um favorecimento de políticas em relação a alguma dimensão específica, o que comprometeria o desenvolvimento, dito sustentável, em qualquer escala de análise.

O tema sustentabilidade tem acelerado o desenvolvimento teórico e prático de um conjunto de indicadores que permitem avaliar o desenvolvimento sustentável de um território (VAN BELLEN, 2005). Neste sentido, vários sistemas de indicadores de desenvolvimento sustentável estão sendo criados, testados e aperfeiçoados na Amazônia (MARCHAND; LE TOURNEAU, 2014) e muitos desses estudos têm adotado o Barômetro da Sustentabilidade-BS (LAMEIRA; VIEIRA; TOLEDO, 2015, CARDOSO; TOLEDO; VIEIRA, 2016; IDESP, 2014), conforme concepção de Prescott-Allen (2001a), por atender os requisitos de precisão e simplicidade, ser didático no entendimento e de fácil motivação para tomadores de decisão (SIENA, 2008).

Em um contexto regional com um dos mais baixos níveis de qualidade de vida do país, espera-se que os planos de desenvolvimento aplicados ao Marajó atendam às necessidades de uma população esquecida pelo poder público há 
séculos. Espera-se ainda, que uma abordagem territorial do desenvolvimento venha fortalecer os grupos sociais locais e buscar a articulação e a sintonia entre as diferentes dimensões do desenvolvimento (CANIELLO; PIRAUX; RAMBO, 2012).

Isto posto, entende-se que as ações de políticas públicas estabelecidas recentemente nos municípios marajoaras tenham oferecido diretrizes e implementado ações voltadas à sustentabilidade socioeconômica e ambiental dos mesmos. Assim, medir o nível de sustentabilidade alcançado pelos municípios desta região é importante no sentido de vislumbrar tendências e comparações relacionadas ao bem-estar humano e ambiental.

Nesta pesquisa, avaliou-se 16 municípios da mesorregião do Marajó, Pará, utilizando o BS como ferramenta de análise, empregando-se 20 indicadores para o bem-estar humano (dimensão socioeconômica) e 06 para o bem-estar ecológico (dimensão ambiental).

\section{METODOLOGIA}

\subsection{CARACTERIZAÇÃO DA ÁREA DE ESTUDO}

O recorte da pesquisa tem como base a mesorregião do Marajó, que abrange uma área de $104.140 \mathrm{Km}^{2}$, ocupada por 16 municípios: Santa Cruz do Arari, Afuá, Anajás, Bagre, Breves, Cachoeira do Arari, Chaves, Curralinho, Gurupá, Melgaço, Muaná, Ponta de Pedras, Portel, Salvaterra, São Sebastião da Boa Vista e Soure, compreendidos nas microrregiões do Arari, Furos de Breves e Portel (Figura 1). A população total dessa região é de 487.010 habitantes, dos quais 56,59\% vivem na área rural (IBGE, 2010).

Apesar de apresentar grande biodiversidade e ser uma região internacionalmente notória, com potencial extraordinário de desenvolvimento, é uma das regiões mais pobres do estado do Pará e do Brasil (BRASIL, 2012; IDESP, 2014). Tem o menor índice de desenvolvimento humano - IDH do estado do Pará $(0,63 \%)$ e também o menor produto interno bruto - PIB per capita (IDESP, 2014). 
Figura 1 - Localização dos municípios da mesorregião do Marajó, estado do Pará

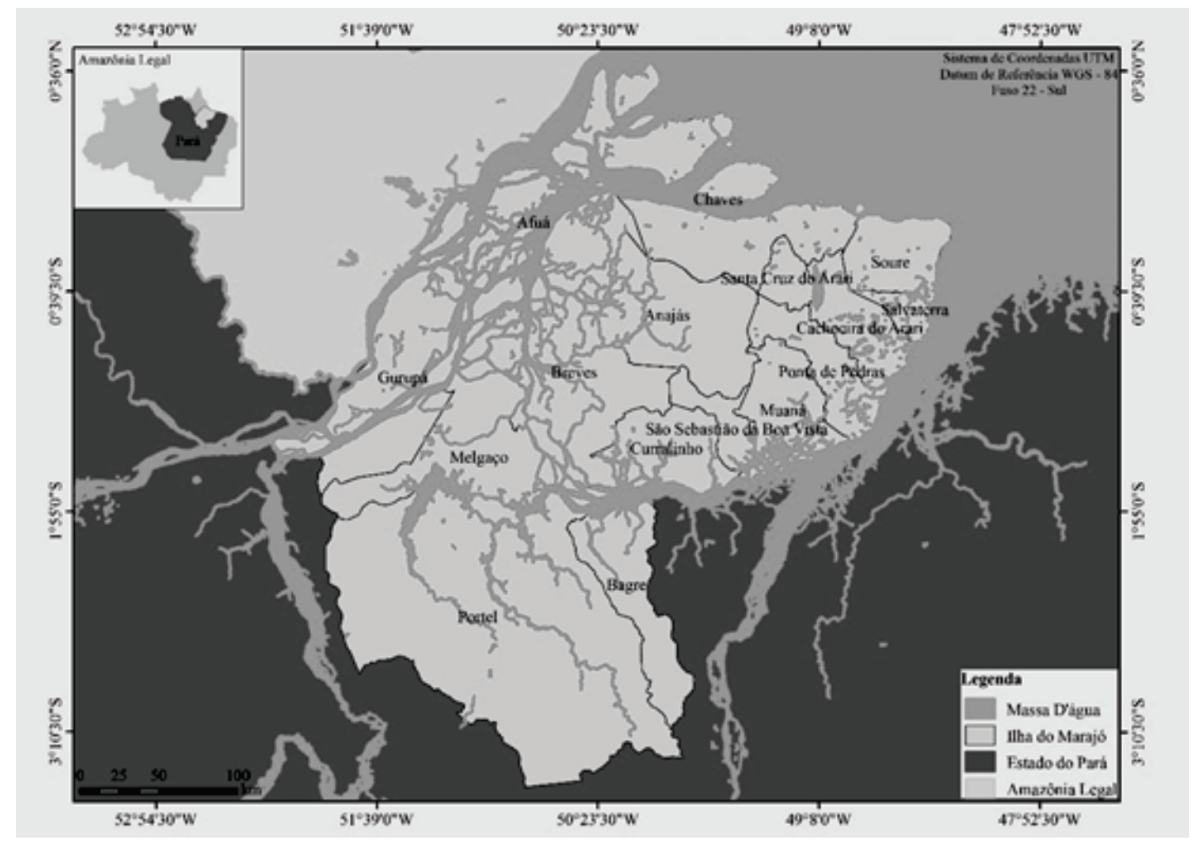

Fonte: Base de dados do IBGE, 2015. Elaboração própria.

\subsection{FERRAMENTA E INDICADORES DE SUSTENTABILIDADE DOS MUNICÍPIOS}

Este estudo aplicou a ferramenta do Barômetro da Sustentabilidade (BS), desenvolvido por diversos especialistas, ligados à IUCN (União Internacional para Conservação da Natureza) e ao IDRC (Centro Internacional de Estudos do Desenvolvimento) (PRESCOT'T-ALLEN, 2001b). O BS utiliza uma combinação de indicadores e seus resultados são demonstrados por meio de índices. Estes índices são apresentados através de uma representação gráfica, procurando facilitar a compreensão e dar um quadro geral do estado do meio ambiente e da sociedade (VAN BELLEN, 2004). Esta representação pode apresentar a dimensão principal de cada índice para realçar aspectos de performance que mereçam mais atenção, sendo adequada também para comparações entre diferentes avaliações (PRESCOTT-ALLEN, 1999, 1997).

Dois grandes eixos são formados: o Bem-Estar Humano (BEHum) e o Bem-Estar do Meio-Ambiente (BEAmb). Cada uma dessas duas grandes dimensões se subdivide em outras cinco dimensões. Para a sociedade considera- 
se: saúde e população, riqueza, conhecimento e cultura, comunidade e equidade. Para o meio ambiente tem-se: terra, ar, água, espécies e utilização de recursos (VAN BELLEN, 2004).

Utilizaram-se 20 indicadores na dimensão humana e 06 indicadores na dimensão ambiental, tendo como base os indicadores utilizados pelo governo do Estado do Pará (IDESP, 2014) como comparativo de desenvolvimento entre os municípios. Além destes, foram incluídos indicadores relacionados à agenda pós 2015 ou Objetivos de Desenvolvimento Sustentável (ODS), estabelecidos pela ONU.

Foram selecionados 26 indicadores, a maioria associados aos Objetivos de Desenvolvimento do Milênio (ODM) e considerados indicadores mais sensíveis às ações imediatas do estado, conforme aponta o Idesp (2014). Assim, foram distribuídos vinte indicadores no Bem-Estar Humano, subdivididos em dimensão social e econômica (Tabelas 1 e 2, respectivamente), e seis indicadores no BemEstar Ambiental, com apenas a dimensão ambiental (Tabela 3). A escolha dos indicadores foi condicionada à existência, consistência dos dados e facilidade de mensuração. Dada às dificuldades inerentes à busca de dados anuais, utilizou-se o período de 2010 a 2014 nesta análise.

Tabela 1 - Temas, indicadores, e parâmetros para construção das escalas de desempenho para a Dimensão Social do BS dos municípios do Marajó, estado do Pará

\begin{tabular}{|c|c|c|c|c|}
\hline \multirow{6}{*}{$\begin{array}{l}\text {.స్త్ర } \\
0 \\
\infty\end{array}$} & Temas & Indicadores & Fonte & Parâmetros \\
\hline & \multirow[t]{5}{*}{$\begin{array}{c}\text { Saúde e } \\
\text { População }\end{array}$} & $\begin{array}{l}\text { Mortalidade } \\
\text { na infância }\end{array}$ & $\begin{array}{c}\text { DATASUS } \\
2013\end{array}$ & $\begin{array}{l}\text { Considera-se Sustentável Mortalidade } \\
\text { na infância (abaixo de } 20 \text { mortes por } \\
\text { mil habitantes) (OMS). }\end{array}$ \\
\hline & & $\begin{array}{c}\text { Mortalidade } \\
\text { materna }\end{array}$ & $\begin{array}{c}\text { DATASUS } \\
2013\end{array}$ & $\begin{array}{l}\text { Considera-se Sustentável Mortalidade } \\
\text { Materna (abaixo de } 20 \text { mortes por } \\
100 \text { mil habitantes) (OMS). }\end{array}$ \\
\hline & & $\begin{array}{l}\text { Número de } \\
\text { médicos }\end{array}$ & $\begin{array}{c}\text { DATASUS } \\
2014\end{array}$ & $\begin{array}{l}\text { Considera-se Sustentável 2,7 médicos } \\
\text { para cada } 1.000 \text { habitantes (Ministério } \\
\text { da Saúde). }\end{array}$ \\
\hline & & $\begin{array}{c}\text { Leitos } \\
\text { hospitalares }\end{array}$ & $\begin{array}{c}\text { DATASUS } \\
2014\end{array}$ & $\begin{array}{l}\text { Considera-se Sustentável } 2,5 \text { a } 3 \\
\text { leitos hospitalares para cada } 1.000 \\
\text { habitantes (Ministério da saúde). }\end{array}$ \\
\hline & & $\begin{array}{l}\text { Gravidez na } \\
\text { infância e } \\
\text { adolescência }\end{array}$ & $\begin{array}{c}\text { DATASUS } \\
2013\end{array}$ & $\begin{array}{l}\text { Considera-se sustentável a não } \\
\text { ocorrência de gravidez nessa faixa } \\
\text { etária, conforme estabelecido nos } \\
\text { Objetivos de Desenvolvimento } \\
\text { Sustentável. }\end{array}$ \\
\hline
\end{tabular}




\begin{tabular}{|c|c|c|c|c|}
\hline \multirow{10}{*}{ 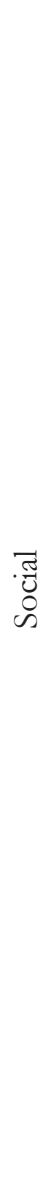 } & \multirow[t]{6}{*}{$\begin{array}{l}\text { Conhecimento } \\
\text { e Cultura }\end{array}$} & $\begin{array}{l}\text { Analfabetis- } \\
\text { mo }\end{array}$ & $\begin{array}{l}\text { IBGE } \\
2010\end{array}$ & $\begin{array}{l}\text { Considera-se sustentável que não } \\
\text { ocorra analfabetismo (ODM). }\end{array}$ \\
\hline & & $\begin{array}{l}\text { Ideb (séries } \\
\text { iniciais) }\end{array}$ & Inep 2013 & $\begin{array}{l}\text { As notas atribuídas pelo IDEB podem } \\
\text { variar de } 0 \text { a } 10 \text {. A meta brasileira, e } \\
\text { também considerado sustentável na } \\
\text { pesquisa, é a obtenção de nota } 6 \text {. }\end{array}$ \\
\hline & & $\begin{array}{l}\text { Ideb (séries } \\
\text { finais) }\end{array}$ & Inep 2013 & $\begin{array}{l}\text { As notas atribuídas pelo IDEB podem } \\
\text { variar de } 0 \text { a } 10 \text {. A meta brasileira, e } \\
\text { também considerado sustentável na } \\
\text { pesquisa, é a obtenção de nota } 6 \text {. }\end{array}$ \\
\hline & & $\begin{array}{l}\text { Evasão esco- } \\
\text { lar ens. Fun- } \\
\text { damental. }\end{array}$ & Inep 2013 & $\begin{array}{lrll}\text { Considera-se sustentável } & 0 \% & \text { de } \\
\text { abandono escolar (ODM). } & & \end{array}$ \\
\hline & & $\begin{array}{c}\text { Evasão } \\
\text { escolar ens. } \\
\text { Médio } \\
\end{array}$ & Inep 2013 & $\begin{array}{lcll}\text { Considera-se } & \text { sustentável } & 0 \% & \text { de } \\
\text { abandono escolar (ODM). } & & \end{array}$ \\
\hline & & $\begin{array}{c}\text { Acesso à } \\
\text { internet }\end{array}$ & $\begin{array}{l}\text { IBGE } \\
2010\end{array}$ & $100 \%$ de cobertura (ODM). \\
\hline & \multirow[t]{3}{*}{ Comunidade } & Roubos & $\begin{array}{l}\text { SEGUP/ } \\
\text { SIAC } 2013\end{array}$ & $\begin{array}{l}\text { Considera-se sustentável } 8 \text { roubos } \\
\text { para cada } 10 \text { mil habitantes } \\
\text { (CIDADES SUSTENTÁVEIS). }\end{array}$ \\
\hline & & Homicídios & $\begin{array}{l}\text { SEGUP/ } \\
\text { SIAC } 2013\end{array}$ & $\begin{array}{l}\text { Considera-se sustentável } 0 \% \text { de } \\
\text { mortes por homicídio (Programa } \\
\text { Cidades Sustentáveis). }\end{array}$ \\
\hline & & $\begin{array}{l}\text { Acesso à } \\
\text { energia } \\
\text { elétrica }\end{array}$ & $\begin{array}{l}\text { IBGE } \\
2010\end{array}$ & $\begin{array}{lrr}\text { Considera-se } & \text { sustentável } & 100 \% \\
\text { de cobertura de Energia } & \text { Elétrica } \\
\text { (IBGE). } & & \\
\end{array}$ \\
\hline & Equidade & $\begin{array}{l}\text { Índice de } \\
\text { Gini }\end{array}$ & $\begin{array}{c}\text { IBGE } \\
2010\end{array}$ & $\begin{array}{l}\text { Considera-se sustentável a não } \\
\text { ocorrência de desigualdade (ODM). }\end{array}$ \\
\hline
\end{tabular}

Fonte: Elaboração própria.

Tabela 2 - Temas, indicadores, e parâmetros para construção das escalas de desempenho para a Dimensão Econômica do BS dos municípios do Marajó, estado do Pará

\begin{tabular}{|c|c|c|c|c|}
\hline \multirow{6}{*}{ 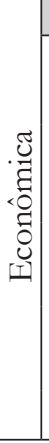 } & Temas & Indicadores & Fonte & Parâmetros \\
\hline & \multirow{5}{*}{ Riqueza } & Extrema pobreza & IBGE 2010 & $\begin{array}{l}\text { Considera-se sustentável a não } \\
\text { existência da extrema pobreza (ODM) }\end{array}$ \\
\hline & & Taxa de atividade & IBGE 2010 & $\begin{array}{c}\text { Considera-se sustentável que } 100 \% \text { da } \\
\text { população ativa esteja ocupada. }\end{array}$ \\
\hline & & Trabalho infantil & IBGE 2010 & $\begin{array}{c}\text { Considera-se sustentável a não } \\
\text { ocorrência do trabalho infantil (OIT) }\end{array}$ \\
\hline & & PIB (per capita) & $\begin{array}{c}\text { IBGE e } \\
\text { IDESP } 2012\end{array}$ & $\begin{array}{l}\text { Consideraram-se os maiores e menores } \\
\text { PIB per capita do Estado do Pará }\end{array}$ \\
\hline & & Renda (per capita) & IBGE 2010 & Entre $\mathrm{R} \$ 624,00$ a $\mathrm{R} \$ 1.157,00$ (PNUD) \\
\hline
\end{tabular}

Fonte: Elaboração própria, 2016. 
Tabela 3 - Temas, indicadores, e parâmetros para construção das escalas de desempenho para a Dimensão Ecológica do BS dos municípios do Marajó, estado do Pará

\begin{tabular}{|c|c|c|c|c|}
\hline \multirow{7}{*}{ 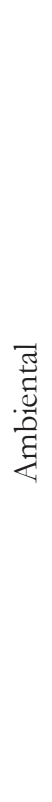 } & Temas & Indicadores & Fonte & Parâmetros \\
\hline & \multirow{2}{*}{ Terra } & $\begin{array}{c}\text { Cadastro } \\
\text { Ambiental Rural }\end{array}$ & Sema 2014 & $\begin{array}{l}\text { Considera-se sustentável acima } \\
\text { de } 80 \% \text { do território com imóveis } \\
\text { rurais inseridos no CAR (MMA) }\end{array}$ \\
\hline & & Desmatamento & $\begin{array}{c}\text { Prodes } \\
2013\end{array}$ & $\begin{array}{c}\text { Considera-se sustentável } \\
\text { Desmatamento inferior a 20\% da } \\
\text { área total do município (MMA) }\end{array}$ \\
\hline & $\mathrm{Ar}$ & Focos de calor & IBGE 2010 & $\begin{array}{l}\text { Considera-se sustentável Até } 10 \\
\text { focos por } 1000 \mathrm{~km}^{2} \text { (considerado } \\
\text { causas naturais) }\end{array}$ \\
\hline & \multirow[b]{2}{*}{ Água } & $\begin{array}{l}\text { Abastecimento } \\
\text { de água }\end{array}$ & IBGE 2010 & $\begin{array}{l}\text { Considera-se sustentável 100\% de } \\
\text { cobertura (IBGE) }\end{array}$ \\
\hline & & $\begin{array}{l}\text { Esgotamento } \\
\text { sanitário }\end{array}$ & \begin{tabular}{c|} 
INPE \\
Queimadas \\
2014 \\
\end{tabular} & $\begin{array}{c}\text { Considera-se sustentável 100\% de } \\
\text { cobertura (IBGE) }\end{array}$ \\
\hline & $\begin{array}{l}\text { Utilização } \\
\text { dos } \\
\text { recursos }\end{array}$ & Coleta de lixo & IBGE 2010 & $\begin{array}{c}\text { Considera-se sustentável 100\% de } \\
\text { cobertura (IBGE) }\end{array}$ \\
\hline
\end{tabular}

Fonte: Elaboração própria.

\subsubsection{Construção das escalas de desempenho}

Após a escolha dos indicadores, foram construídas as Escalas de Desempenho Municipal (EDM), a qual é utilizada para avaliar a situação do indicador em relação à meta ou padrão estabelecido, e aplicado a diferentes períodos, possibilitando o monitoramento de avanços e retrocessos em direção ao desenvolvimento sustentável (KRONEMBERGER et al., 2004). A definição dos limites das EDM foi feita a partir de valores pesquisados na literatura especializada, tais como padrões definidos na legislação ou metas estabelecidas nacionais ou internacionalmente. A metodologia seguida nesse estudo para todos os indicadores foi baseada em estudo feito por Kronemberger, et al. (2004), compostas a partir da divisão do intervalo entre os extremos em cinco setores iguais, variando de insustentável a sustentável (Tabelas 4, 5 e 6). 
Tabela 4 - Escalas de desempenho dos indicadores municipais da dimensão social e sua transposição para a escala do Barômetro da Sustentabilidade dos 16 municípios da mesorregião do Marajó, Pará

\begin{tabular}{|c|c|c|c|c|c|}
\hline \multirow{4}{*}{ Indicadores municipais } & \multicolumn{5}{|c|}{$\begin{array}{c}\text { ESCALA DE DESEMPENHO DO BARÔMETRO } \\
\text { DA SUSTENTABILIDADE }\end{array}$} \\
\hline & $0-20$ & $21-40$ & $41-60$ & $61-80$ & $81-100$ \\
\hline & $\begin{array}{l}\text { Insusten- } \\
\text { tável }\end{array}$ & $\begin{array}{l}\text { Potenc } \\
\text { Insust. }\end{array}$ & $\begin{array}{l}\text { Interme- } \\
\text { diário }\end{array}$ & $\begin{array}{c}\text { Potenc. } \\
\text { Sust. }\end{array}$ & $\begin{array}{l}\text { Susten- } \\
\text { tável }\end{array}$ \\
\hline & \multicolumn{5}{|c|}{ ESCALA DE DESEMPENHO MUNICIPAL } \\
\hline Mortalidade na infância & $100-76$ & $75-50$ & $49-20$ & $19-20$ & $19-0$ \\
\hline Mortalidade materna & $800-150$ & $149-50$ & $49-20$ & $19-10$ & $9-0$ \\
\hline Número de médicos & $0-0,3$ & $0,4-0,6$ & $0,7-1,3$ & $1,4-2,6$ & $2,7-5$ \\
\hline Leitos hospitalares & $0-0,5$ & $0,6-1,9$ & $2-2,4$ & $2,5-2,9$ & $3-1$ \\
\hline $\begin{array}{l}\text { Gravidez na infância e } \\
\text { adolescência }\end{array}$ & $100-10,1$ & $10-5,1$ & $5-3,1$ & $3-1$ & $0,99-0$ \\
\hline Analfabetismo & 100-20,1 & $20-10,1$ & $10-5,1$ & $5-1$ & $0,99-0$ \\
\hline Ideb (séries iniciais) & $0-1,9$ & $2-3,9$ & $4-5,9$ & $6-7,9$ & $8-10$ \\
\hline Ideb (séries finais) & $0-1,9$ & $2-3,9$ & $4-5,9$ & $6-7,9$ & $8-10$ \\
\hline $\begin{array}{l}\text { Evasão escolar ens. } \\
\text { Fundamental. }\end{array}$ & $100-20,1$ & $20-10,1$ & $10-5,1$ & $5-1$ & $0,99-0$ \\
\hline Evasão escolar ens. Médio. & $100-20,1$ & $20-10,1$ & $10-5,1$ & $5-1$ & $0,99-0$ \\
\hline Acesso à internet & $0-20$ & $21-40$ & $41-60$ & $61-80$ & $81-100$ \\
\hline Roubos & $400-33$ & $32-25$ & $24-17$ & $16-9$ & $8-0$ \\
\hline Homicídios & $300-50,1$ & $50-20,1$ & $20-10,1$ & $10-5$ & $4,99-0$ \\
\hline Acesso à energia elétrica & $0-69$ & $70-79$ & $80-89$ & $90-94$ & $95-100$ \\
\hline Índice de Gini & $1-0,81$ & $0,8-0,51$ & $0,5-0,41$ & $0,4-0,21$ & $0,2-0$ \\
\hline
\end{tabular}

Fonte: Elaboração própria. 
Tabela 5 - Escalas de desempenho dos indicadores municipais da dimensão econômica e sua transposição para a escala do Barômetro da Sustentabilidade dos 16 municípios da mesorregião do Marajó, Pará

\begin{tabular}{|c|c|c|c|c|c|}
\hline \multirow{5}{*}{$\begin{array}{l}\text { Indicadores } \\
\text { municipais }\end{array}$} & \multicolumn{5}{|c|}{$\begin{array}{l}\text { ESCALA DE DESEMPENHO DO BARÔMETRO DA } \\
\text { SUSTENTABILIDADE }\end{array}$} \\
\hline & $0-20$ & $21-40$ & $41-60$ & $61-80$ & $81-100$ \\
\hline & \multirow{2}{*}{ Insustentável } & Potenc. & \multirow{2}{*}{ Intermediário } & Potenc. & \multirow{2}{*}{ Sustentável } \\
\hline & & Insust & & Sust. & \\
\hline & \multicolumn{5}{|c|}{ ESCALA DE DESEMPENHO MUNICIPAL } \\
\hline Extrema pobreza & $100-50,1$ & $50-20,1$ & $20-10,01$ & $10-5$ & $4,99-0$ \\
\hline Taxa de atividade & $0-20$ & $21-40$ & $41-60$ & $61-80$ & $81-100$ \\
\hline Trabalho infantil & $100-10,1$ & $10-5,1$ & $5-3,1$ & $3-1$ & $0,99-0$ \\
\hline PIB (per capita) & $0-6793$ & $\begin{array}{c}6794- \\
12.006\end{array}$ & 12.007-18.159 & $\begin{array}{l}18160- \\
32.901\end{array}$ & $\begin{array}{c}35.641- \\
200.000,00\end{array}$ \\
\hline Renda (per capita) & $96-180$ & $181-333$ & $334-624$ & $625-1157$ & $1158-2000$ \\
\hline
\end{tabular}

Fonte: Elaboração própria, 2016.

Tabela 6 - Escalas de desempenho dos indicadores municipais da dimensão ecológica e sua transposição para a escala do Barômetro da Sustentabilidade dos 16 municípios da mesorregião do Marajó, Pará

\begin{tabular}{|c|c|c|c|c|c|}
\hline \multirow{5}{*}{ Indicadores municipais } & \multicolumn{5}{|c|}{$\begin{array}{l}\text { ESCALA DE DESEMPENHO DO BARÔMETRO } \\
\text { DA SUSTENTABILIDADE }\end{array}$} \\
\hline & $0-20$ & $21-40$ & $41-60$ & $61-80$ & $81-100$ \\
\hline & \multirow{2}{*}{$\begin{array}{l}\text { Insusten- } \\
\text { tável }\end{array}$} & Potenc & \multirow{2}{*}{$\begin{array}{l}\text { Interme- } \\
\text { diário }\end{array}$} & Potenc & \multirow{2}{*}{$\begin{array}{c}\text { Sustentá- } \\
\text { vel }\end{array}$} \\
\hline & & Insust. & & Sust. & \\
\hline & \multicolumn{5}{|c|}{ ESCALA DE DESEMPENHO MUNICIPAL } \\
\hline Cadastro Ambiental Rural & $0-20$ & $21-40$ & $41-60$ & $61-80$ & $81-100$ \\
\hline Desmatamento & $300-161$ & $160-121$ & $120-81$ & $80-41$ & $40-0$ \\
\hline Focos de calor & $200-41$ & $40-31$ & $30-21$ & $20-11$ & $10-0$ \\
\hline Abastecimento de água & $0-69$ & $70-79$ & $80-89$ & $90-94$ & $95-100$ \\
\hline Esgotamento sanitário & $0-69$ & $70-79$ & $80-89$ & $90-94$ & $95-100$ \\
\hline Coleta de lixo & $0-69$ & $70-79$ & $80-89$ & $90-94$ & $95-100$ \\
\hline
\end{tabular}

Fonte: Elaboração própria. 


\subsubsection{Cálculo e ordenamento dos resultados}

Após a elaboração das Escalas de Desempenho (ED), foi feita a transposição do valor numérico do indicador municipal (EDR) para a Escala do BS (EBS), através de interpolação linear simples, de forma a atribuir grau ao indicador na Escala do Barômetro da Sustentabilidade, através da seguinte fórmula:

$$
E B S x=\left\{\left[\frac{\left(E D I_{a}-V R_{x}\right) x\left(E B S_{a}-E B S_{p}\right)}{\left(E D I_{a}-E D I_{p}\right)}\right] x(-1)\right\}+E B S_{a}
$$

Onde: $V \mathrm{R}_{x}=$ valor real do indicador $\mathrm{x}$;

$\mathrm{a}=$ limite anterior do intervalo que contém $V \mathrm{R}_{x}$;

$\mathrm{p}=$ limite posterior do intervalo que contém $V R_{x}$.

Após os cálculos individuais de cada indicador na escala do BS, esses foram agregados hierarquicamente de forma que se obteve a média aritmética dos indicadores de cada tema, e então, calculou-se um índice para cada dimensão (ambiental, social, e econômica) através da média aritmética dos temas correspondentes. Por último, calculou-se dois índices para cada município da mesorregião do Marajó, correspondentes aos subsistemas sociedade e natureza: Índice de Bem-Estar Humano e Índice de Bem-Estar Ambiental.

\section{RESULTADOS E DISCUSSÃO}

Os índices de bem-estar humano (BEHum) e o de bem-estar ambiental (BEAmb), podem ser vistos na Figura 2. Pode-se afirmar que para a maioria dos municípios, o BEAmb está numa faixa aceitável de sustentabilidade (intermediário), e apenas Santa Cruz do Arari e Curralinho estão na faixa de potencialmente insustentável. Já o BEHum dos municípios apresenta-se na faixa classificada como de sustentabilidade pobre, mais próximo da insustentabilidade, com apenas quatro municípios na faixa intermediária (Gurupá, Salvaterra, Santa Cruz do Arari e Soure). Os municípios que atingiram o patamar mínimo de sustentabilidade (intermediário) foram Gurupá, Salvaterra e Soure. Observa-se, ainda, que as diferentes performances dos municípios do Marajó em relação ao BEHum e BEAmb confirmam que as ações municipais podem ser identificadas como a causa principal desta grande variabilidade nos indicadores e que o papel da gestão municipal em implementar políticas e programas é determinante no nível de sustentabilidade. 
Figura 2 - Visualização espacial dos índices de Bem-Estar Humano e Bem-Estar Ambiental nos16 municípios da mesorregião do Marajó, Pará

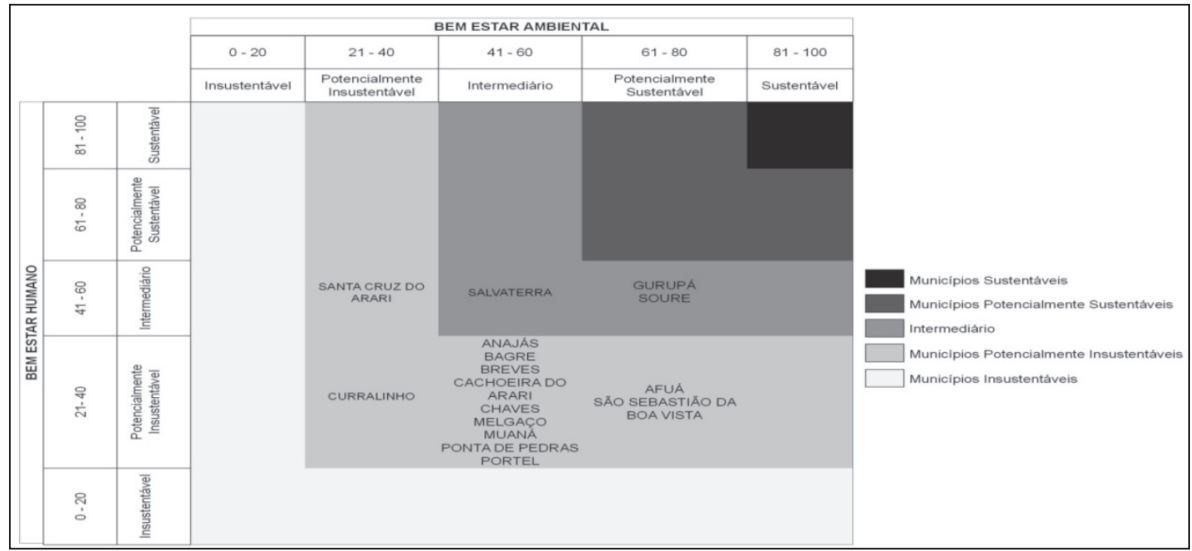

Fonte: Elaboração própria.

Dos municípios potencialmente insustentáveis, nota-se que Anajás, Melgaço, Breves e Afuá apresentam padrões similares de desenvolvimento, com melhor desempenho no eixo do BEAmb (Figura 3). Por outro lado, Santa Cruz do Arari, Muaná, Cachoeira do Arari e Curralinho, têm os piores desempenhos ambientais. $O$ município de Santa Cruz do Arari, apesar de estar situado na faixa Potencialmente Insustentável, obteve o melhor desempenho no eixo do BEHum, seguido por Salvaterra, Gurupá e Soure, situados na faixa do Intermediário. Os municípios de Afuá e Portel apresentaram os piores desempenhos do eixo do BEHum.

Figura 3 - Gráfico com representação das escalas de sustentabilidade do BS dos municípios da mesorregião do Marajó, Pará

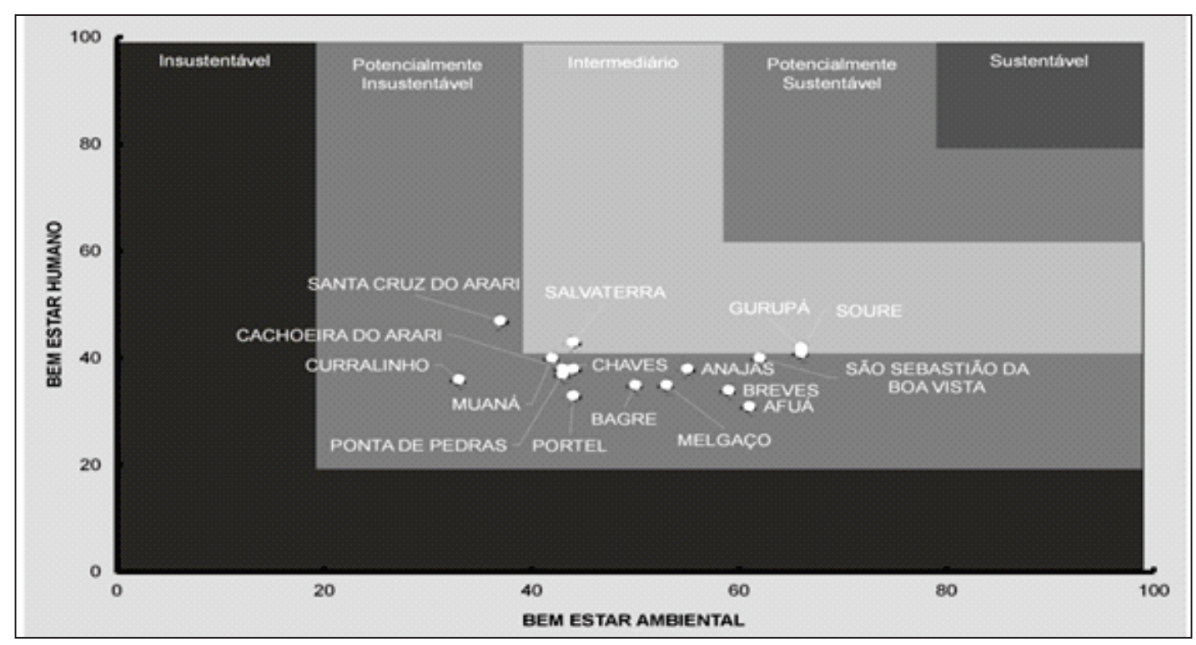

Fonte: Elaboração própria 
O panorama da sustentabilidade gerado por este estudo mostrou que o eixo do BEHum é bastante crítico nos municípios do Marajó, apresentando baixos índices de sustentabilidade e situações preocupantes de acesso aos direitos básicos. Os indicadores da dimensão social (Saúde e População, Conhecimento e Cultura, Comunidade, Equidade) evidenciam que essa região tem baixa eficácia e capilaridade das políticas públicas, de serviços de infraestrutura para promoção e proteção social voltadas ao desenvolvimento. Ribeiro (2002), ao calcular índices de sustentabilidade para cidades e regiões do estado do Pará, para o ano 2000, tendo como base uma proposta de modelo de indicadores para a Amazônia (IASAM), encontrou que a mesorregião do Marajó é uma das mais insustentáveis. Alta taxa de mortalidade infantil, poucas áreas municipais de proteção ambiental, PIB per capita com ondas de crescimento e queda num período de 20 anos e baixa participação política fornecem uma leitura de baixa sustentabilidade em todos os aspectos dentro da mesorregião.

$\mathrm{O}$ acesso à infraestrutura, mesmo descrita como prioritária em diversos planos estratégicos para o Marajó (BRASIL, 2004; ZEE - PARÁ, 2005, BRASIL, 2007), tem sido ausente na região e isso tem produzido problemas de saúde e de segurança alimentar. É alarmante o número de crianças nascidas por mães também "crianças" na região, com valores inaceitáveis nos municípios analisados. As altas taxas de gravidez na infância e adolescência são reflexos de uma fragilidade na estrutura social, e influenciaram o nível de potencial insustentabilidade alcançado pelos municípios marajoaras. Outros aspectos relevantes decorrentes deste padrão de insustentabilidade encontrado são as altas taxas de mortalidade na infância, de analfabetos, de evasão escolar e trabalho infantil, dentre outros indicadores que, quando acompanhados, podem explicar uma grande parcela dos problemas sociais recorrentes no Marajó.

Diante de um quadro persistente de estagnação econômica e com a finalidade de sanar as problemáticas existentes no território, o Plano Marajó Sustentável-PDTS (BRASIL, 2007) visava alterar esta realidade e estabelecer novas diretrizes a fim de atender demandas específicas de cada município. Neste plano estavam incluídas diversas metas para reverter o quadro socioeconômico da região, assim como fortalecer a organização do sistema público de saúde, apoiar os mecanismos de participação e organização da comunidade, objetivando o fim de práticas de exploração humana (trabalho infantil, exploração sexual de menores, tráfico de mulheres etc.) e o fortalecimento da cidadania (BARROS, 2013). A partir de uma metodologia inclusiva, o PDTS foi um marco no planejamento territorial e gerou enormes expectativas na população marajoara, porém, falhou em sua execução. Este estudo com o BS mostra um quadro de 
baixo desenvolvimento sustentável na região e isto, na prática, revela que não houve grandes modificações na estrutura socioeconômica do Marajó com os programas territoriais criados. O desenvolvimento sustentável do Marajó continua sendo um grande desafio para a sociedade brasileira.

\section{CONCLUSÕES}

O Barômetro da Sustentabilidade pode ser considerado uma ferramenta eficaz de avaliação da sustentabilidade, com potencial para incorporação nos processos de tomada de decisão que permitem a avaliação sistemática do bem estar humano e ambiental em nível local. Conforme apresentado, o Marajó mostrou um quadro de desequilíbrio em relação ao nível de sustentabilidade dos municípios, e a isso associamos a ineficácia dos resultados de políticas públicas integradas aliada à discrepância dos diferentes modelos de gestão municipal. Mesmo com a existência de várias propostas para restruturação do território sob a regência de planos de desenvolvimento sustentável, esta região não apresentou transformações sociais significativas na última década. Este quadro de fragilidade no processo de desenvolvimento sustentável expõe o Marajó a ações de projetos econômicos com alto potencial de risco de degradação ambiental num quadro de baixa resiliência social.

\section{AGRADECIMENTOS}

Os autores agradecem ao apoio do INCT/Biodiversidade e Uso da Terra na Amazônia (processo CNPq no 574008/2008-0), pelo financiamento para a realização dos trabalhos de campo, e concessão da bolsa de estudo pelo CNPq ao Patrick Quintela (Mestrado) e ao Programa de Pós-Graduação de Ciências Ambientais da Universidade Federal do Pará.

\section{REFERÊNCIAS}

BARROS, M. J. B. Uma análise crítica do Plano de Desenvolvimento Territorial Sustentável do Arquipélago do Marajó-Pará. GeoAmazônia, n. 01, v. 01, p. 40 - 54, 2013. DOI: 10.17551/2358-1778. Disponível em: <http://www.geoamazonia. net/index.php/revista/article/view/5/pdf_4>. Acesso em: abr. 2016

BRASIL. Ministério do Desenvolvimento Agrário. Relatório Analítico do Território do Marajó. Belém, 2012. Disponível em <http://sit.mda.gov.br/ download/ra/ra129.pdf>. Acesso em: abr. 2016. 
Governo Federal. Grupo Executivo Interministerial. Plano de Desenvolvimento Territorial Sustentável para o Arquipélago do Marajó: resumo executivo da versão preliminar para discussão nas consultas públicas. Brasília, Editora do Ministério da Saúde, 2007. 24 p. Disponível em: <http:// www.seplan.pa.gov.br/sites/default/files/PDF/ppa/ppa2016-2019/pdrs_ marajo.pdf $>$. Acesso em: abr. 2016.

Presidência da República. Casa Civil. Plano de Desenvolvimento Territorial Sustentável para o Arquipélago do Marajó. Brasília, 2007. Disponível em <http://www.mi.gov.br/c/document_library/get_ file?uuid $=9408 \mathrm{a} 880-6 e c 0-4 \mathrm{be} 0-9 \mathrm{cb} 7-$ feb01c4a6256\&groupId=24915>. Acesso em: abr. 2016.

Plano Amazônia Sustentável. 2004. Disponível em <http://www. ufmt.br/sinop/arquivos/c2b508dde9fbdc39679ee41525e12cae.pdf>. Acesso em: abr. 2016.

CANIELLO, M.; PIRAUX, M.; RAMBO, A. G. As políticas públicas territoriais e desenvolvimento rural sustentável no Brasil Contemporâneo. In: ENCONTRO DA REDE DE ESTUDOS RURAIS. Belém, 2012. Anais Eletrônicos... Belém: UFPA, 2012. Disponível em: <http://agritrop.cirad.fr/567066/1/ document_567066.pdf>. Acesso em: Acesso em: abr. 2016.

CARDOSO, A.S;TOLEDO, P.M; VIEIRA, I. C. G. Barômetro da sustentabilidade aplicado ao município de Moju, estado do Pará. Revista Brasileira de Gestão e Desenvolvimento Regional, Taubaté, v. 12, n. 1, p. 234-263, jan/abr. 2016

IBGE, Cidades. 2010. Disponível em: <http://www.cidades.ibge.gov.br/xtras/ uf.php?lang=\&coduf=15\&search=para $>$. Acesso em: 10 jul. 2015.

IDESP. Indicadores de qualidade ambiental dos municípios da região de integração do Marajó. Secretaria de Estado de Gestão. Belém, 2014.

INSTITUTO PEABIRU. Diagnóstico Socioeconômico, Ambiental e Cultural do Arquipélago do Marajó. 109 p. 2012. Disponível em: <https:// institutopeabiru.files.wordpress.com/2012/09/vivamarajo-escutamarajo.pdf $>$. Acesso em: Acesso em: ago. 2016.

KRONEMBERGER, D. M. P.et al. Indicadores de Sustentabilidade em Pequenas Bacias Hidrográficas: Uma Aplicação do Barômetro da Sustentabilidade à Bacia do Jurumirim (Angra dos Reis, RJ). Geochemical Brasiliensis, v.18, n.2. , 2004 Disponível em: <http://geobrasiliensis.org.br/ojs/index.php/geobrasiliensis/ article/viewFile/214/pdf>. Acesso: Acesso em: abr. 2016. 
LAMEIRA, W. J. M; VIEIRA, I. C. G; TOLEDO, P. M. Panorama da Sustentabilidade na Fronteira Agrícola de Bioenergia na Amazônia. Sustentabilidade em Debate, Brasília, v. 6, n. 2, p. 193-210, mai/ago. 2015.

MARCHAND, G; LE TOURNEAU, F. M. O desafio de medir a sustentabilidade na Amazônia: os principais indicadores e a sua aplicabilidade ao contexto amazônico. In: VIEIRA, I. C. G; TOLEDO, P. M; SANTOS JÚNIOR, R. A. O (orgs.). Ambiente e sociedade na Amazônia: uma abordagem interdisciplinar. Rio de Janeiro: Garamond, 2014. p. 155-220.

PARÁ, Macrozoneamento Ecológico-Econômico do Estado do Pará: Lei N ${ }^{\circ}$ 6.745, 6 de maio de 2005.

PRESCOTT-ALLEN, R. The Barometer of Sustainability. IUCN, 2001a. Disponível em: <http://www.iucn.org/themes/eval/english/barom.htm>. Acesso em: set. 2015.

Wellbeing of Nations (The)A country-by-country index of quality of life and the environment. Washington, IDRC/Island Press, 2001b. 350p.

Assessing Progress toward Sustainability: The System Assessment Method illustrated by the Wellbeing of Nations. Cambridge: IUCN, 1999.

Barometer of Sustainability: Measuring and communicating wellbeing and sustainable development. Cambridge: IUCN, 1997.

RIBEIRO, A. L. Modelo de indicadores para mensuração do desenvolvimento sustentável na Amazônia. 2002. Tese (Doutorado em Desenvolvimento Sustentável do Trópico UÚmido) - Núcleo de Altos Estudos Amazônicos, Universidade Federal do Pará, Belém, 2002.

SIENA, O. Método para avaliar desenvolvimento sustentável: técnicas para escolha e ponderação de aspectos e dimensões. Produção, São Paulo, v. 18, n. 2, p. 359-374, 2008. Disponível em: <http://www.scielo.br/scielo.php?script=sci_arttext\&pid=S010365132008000200012\&lng=en\&nrm=iso >. Acesso em: 14 ago. 2017.

VAN BELLEN, H. M. V. Indicadores de sustentabilidade: uma análise comparativa. Rio de Janeiro: FGV, 2005.

Desenvolvimento Sustentável: uma descrição das principais ferramentas de avaliação. Ambiente \& Sociedade, v. 7, n. 1, p. 67-88, 2004. Disponível em: <http://www.scielo.br/pdf/asoc/v7n1/23537.pdf>. Acesso em: 14 ago. 2017. 
